\title{
Basic Characteristics of Rail Brake Systems Using Linear Motor Technology
}

\author{
Takayuki KASHIWAGI \\ Assistant Senior Researcher \\ Yasuaki SAKAMOTO \\ Takashi SASAKAWA, Ph.D. \\ Assistant Senior Researcher Senior Researcher, Laboratory Head, \\ Electromagnetic Applications Laboratory, Maglev Systems Technology Division
}

\author{
Minoru TANAKA, Ph.D. \\ Assistant Senior Researcher, \\ Electromagnetic Guideway Technology Laboratory, Maglev Systems Technology Division
}

\author{
Yasushi KARINO \\ Senior Researcher, \\ Brake Control Laboratory, Vehicle Control Technology Division
}

\begin{abstract}
An eddy-current rail brake system is effective in stabilizing the braking ability of trains because its braking force does not depend on adhesion between the wheel and the rail. However, the use of the existing type equipped with DC electromagnets causes the rail temperature to increase, bringing the possibility of rail bending. Because of this, it is impractical for use in Japan. Accordingly, we applied an AC electromagnet (the same as those used in linear induction motors) to the rail brake system to reduce rail temperature rise, and investigated its basic characteristics using a rotary-type test machine.
\end{abstract}

Keywords: rail brake, linear induction motor, rail heating

\section{Introduction}

The role of braking equipment that stops vehicles becomes more important as train speeds increase. Although various methods are used in braking equipment for railway vehicles, the braking force depends almost entirely on adhesion between the wheel and the rail. The frictional coefficient of wheels and rails is also prone to variation, and is affected by train speeds, weather-related factors such as rain, and the condition of wheels and rails (surface roughness, rust, etc.). Accordingly, various methods have been designed to achieve constant braking force and incorporated into practical application, such as the presumption of frictional coefficients for brake control [1] and the scattering of adhesion-improvement materials [2].

Conversely, the braking force of the eddy-current rail brake [3] does not depend on adhesion between the rail and the wheel, but problems related to rail temperature rise when using these brakes with $\mathrm{DC}$ excitation make them impractical for use in Japan. However, applying an $\mathrm{AC}$ electromagnet (the same as those used in linear induction motors) to the eddy-current rail brake system diminish this rail temperature rise. In this paper, we report on the basic characteristics of this new-type eddycurrent rail brake investigated using a rotary-type test machine. We also performed a starting characteristics test on a control scheme that can be operated using a low voltage/small-capacity electric power source such as the control power supply. In addition, we compared several types of winding method and performed examination through electromagnetic analysis to survey any problems related to rail brake installation on the truck. The results of this work are reported below.

\section{Eddy-current rail brake}

There are three types of rail brake:

(1) The eddy-current rail brake, which generates eddy-current in rails using a magnetic field and produces braking force with no contact.

(2) The electromagnetic rail brake, which attracts rail braking equipment to the rail using a magnetic field and produces braking force using a friction material.

(3) The hybrid rail brake, which combines types (1) and (2) as referred in [4].

Types (2) and (3) above have the problem of changing the frictional coefficients and galling of the brake system and the rail, because the braking equipment contacts the rail itself. Accordingly, in this study we examined the nonfrictional eddy-current rail brake. The difference between the eddy-current rail brake using the DC excitation method (i.e., the type examined so far) and that using the AC excitation method for application to linear motors is described below.

The eddy-current rail brake that produces braking force by non-contact has a number of common problems, including the need to increase the total current value, the winding diameter for excitation and the capacity of the excitation power supply to the electromagnet. These problems stem from the necessity of generating a magnetic field between the rail and the rail brake over a fairly large mechanical gap.

\subsection{Eddy-current rail brake with DC excitation}

Figure 1 shows a conceptual diagram of the eddy-current rail brake using DC excitation, which is the main type of rail brake developed so far. Electromagnets with 


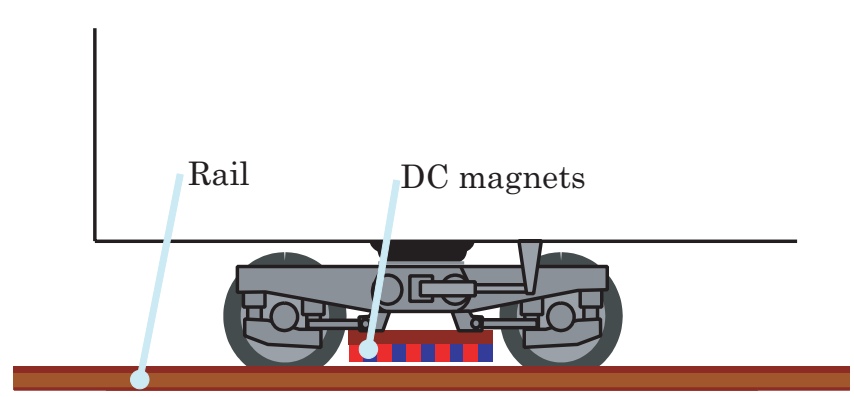

Fig. 1 DC-excitation eddy-current rail brake

several pair of N-pole/S-pole formation are placed parallel to the rail. When the brake is activated, a direct current excites the electromagnet. When an eddy-current is generated on the rail in the magnetic field resulting from the electromagnet's movement along the rail with the motion of the vehicle, the car's kinetic energy causes heat generation in the rail, and a braking force is produced. Japanese National Railways studied this type of eddycurrent rail brake prior to the opening of the Sanyo Shinkansen, and test running was executed on the Tokaido Shinkansen track. However, this type of eddycurrent rail brake is not in practical use in Japan because of the problem of increased rail temperatures, although it has been conditionally incorporated into practical use on Germany's ICE 3 high-speed electric train. The power supply unit and composition of this type rail brake are simpler than those of the AC-excitation eddy-current rail brake described later.

\subsection{Eddy-current rail brake with AC excitation}

Figure 2 shows a conceptual diagram of the eddy-current rail brake using $\mathrm{AC}$ excitation. The electromagnet that creates the AC magnetic field is placed parallel to the rail. When the brake is activated, a three-phase current excites the electromagnet. As the linear induction motor is composed of the AC energization electromagnet and the rail as reaction plate, it is possible to use the rail brake as a linear induction generator. Accordingly, the AC-excitation eddy-current rail brake can convert kinetic energy to electrical energy on board through dynamic braking. Since energy is collected on board, the rail temperature rise generated with the same braking force is essentially less than that of the DC-excitation eddy-current rail brake.

Moreover, if a lower-capacity power supply can be used

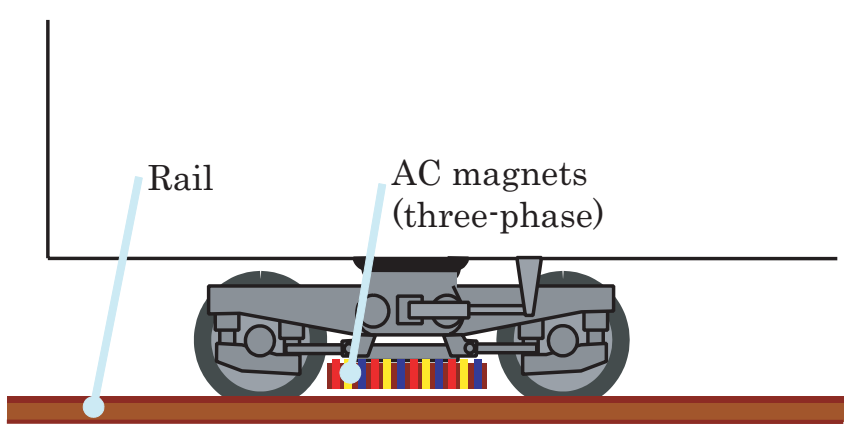

Fig. 2 AC-excitation eddy-current rail brake to initiate excitation, the use of collected energy to activate the rail brake removes the need for an external energy supply. This makes the AC excitation rail brake advantageous. However, an additional inverter is needed. Figure 3 shows an example of such a setup.

With this method, rail brake operation starts with a low voltage/low-capacity electric power supply such as that used for auxiliary power, and in steady operation a part of the kinetic energy generated is converted to electrical power by the rail brake. Two system configurations (Fig. 4) can be set through different inverter control. These are:

(a) High generation of electric power and stronger mitigation of rail temperature rise.

(b) Low generation of electric power and removal of the need for a resistor and chopper, enabling a reduction in the amount of on-board equipment.

In particular, the composition of (b) enables the power supply system of the rail brake to be made independent of the main circuit of the drive motor and the feeding system.

Low voltage/low capacity

power supply

(e.g. auxiliary power) Chopper and resistor

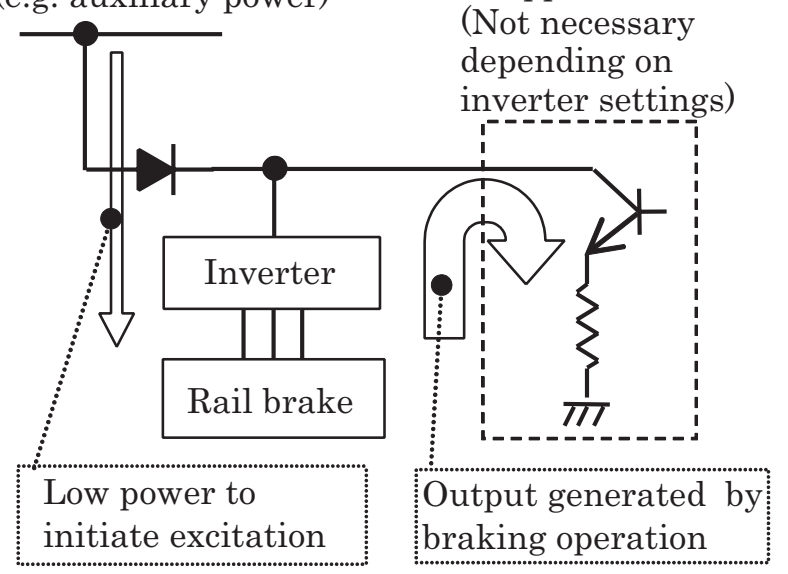

Fig. 3 Example circuit of rail brake system

\begin{tabular}{|l|l|l|}
\cline { 2 - 2 } *Enhanced reduction of & $\begin{array}{l}\text { *Resistor for } \\
\text { rail temperature rise }\end{array}$ & $\begin{array}{l}\text { dynamic braking } \\
\text { unnecessary } \\
\text { *Large inverter } \\
\text { capacity required }\end{array}$ \\
\hline
\end{tabular}

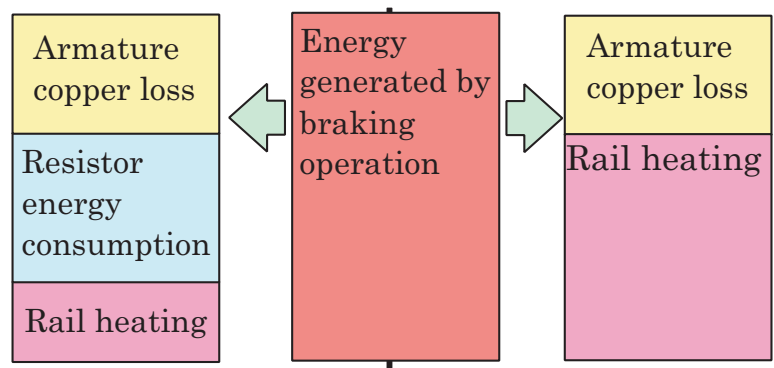

(a) Focus on reduction I (b) Focus on minimization of rail temperature rise of equipment

Fig. 4 Difference in energy flow with the inverter control method 
On the other hand, the linear motor using the ACexcitation eddy-current rail brake has two features that differ from those of regular linear motors. These are:

(1) The secondary conductor (the rail) is composed only of high-resistivity iron.

(2) Depending on the construction of the rail brake system, the linear motor incorporating the AC-excitation eddy-current rail brake has a peculiar shape with a very narrow width on the secondary conductor (the rail) compared to the pole pitch of the electromagnet on the primary armature (the on-board rail brake).

In (1) above, because the skin depth of the induced current in the secondary conductor is small, the induced current and magnetic flux are concentrated on the surface of the rail (a phenomenon known as the skin effect), and efficiency in the low slip area is reduced. In (2), the limitation on the tie direction of the induced current on the surface of the rail causes a reduction of braking force in the rail brake. Moreover, the low power factor causes problems requiring an increase in the power supply equipment's capacity. We performed the examinations outlined below to confirm these basic characteristics.

\section{Confirmation of basic characteristics using a rotary- type test machine}

The AC-excitation eddy-current rail brake basically has the composition of a linear induction motor as described in Chapter 2. An induction motor generates thrust by the relative motion of a shifting field on a primary armature and a secondary conductor. To confirm the basic characteristics of the rail brake, we fabricated a rotary-type test machine with a solid steel rotor by remodeling a conventional squirrel cage induction motor. Two types of rotor were prepared. One was a wide rotor with a width the same as the original rotor to evaluate the effect of (1) described in paragraph 2.2. The other was a narrow rotor with a width the same as the rail to evaluate the effect of (2) described in paragraph 2.2. However, a linear motor has an end effect different from a regular motor, which may have a large effect on the characteristics. Accordingly, here we focused on problems peculiar to the rail brake, and the end effect will be confirmed through further testing and analysis. Although the mechanical gap with a regular induction motor is approximately $1-2 \mathrm{~mm}$, when mounting of the rail brake on the truck is assumed, it is impossible to set the same mechanical gap between the rail and the rail brake as in a regular induction motor, so in this examination the gap was set to $5 \mathrm{~mm}$.

\subsection{Test machine configuration}

Figure 5 shows the experimental apparatus for the rotary-type test machine. A variable voltage and variable frequency (VVVF) inverter are used to supply a threephase current of variable voltage and variable frequency to the armature (simulated as the rail brake armature) of the test machine. The rotor (corresponding to the rail) of the test machine is rotated by the drive motor, and running conditions at an arbitrary speed are simulated. The current and voltage supplied to the test machine are measured, and the amount of electric power is calculated from the results. A torque detector and tachometer are connected to the axis of the test machine, and the machine input is also calculated from the measurement results. From the electric power and mechanical input, the braking force of the rail brake and the rail heating reduction ratio are calculated. The formula used to calculate

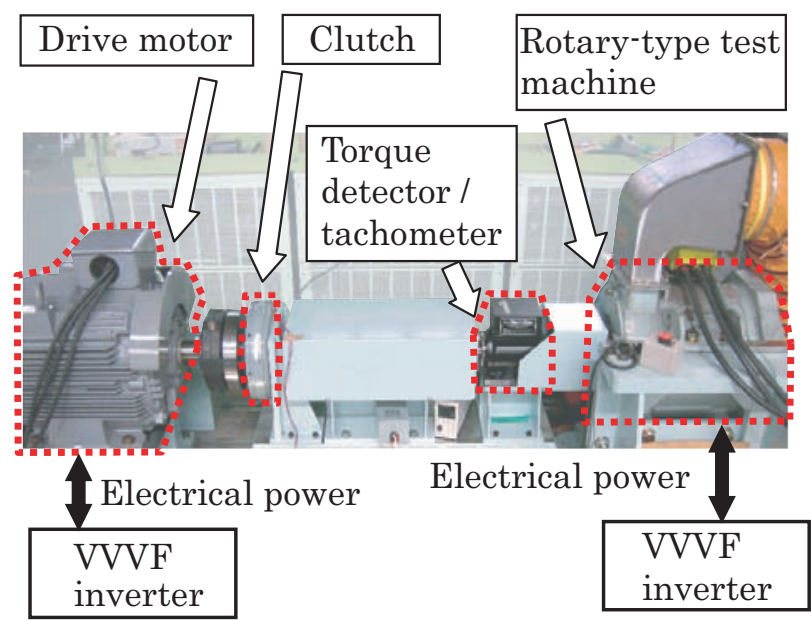

Fig. 5 Experimental apparatus for the rotary-type test machine

Table 1 Specifications of the rotary-type test machine

\begin{tabular}{c|l}
\hline Rated output & $255 \mathrm{~kW}$ (before modification) \\
\hline Number of poles & 4 \\
\hline $\begin{array}{c}\text { Stator width } \\
\text { (primary iron) }\end{array}$ & $175 \mathrm{~mm}$ \\
\hline Rotor width & $175 \mathrm{~mm}$ \\
& $($ Wide rotor) \\
& $65 \mathrm{~mm}$ \\
& $($ Narrow rotor) \\
\hline Mechanical gap & $5 \mathrm{~mm}$ \\
\hline Stator inner diameter & $270 \mathrm{~mm}$ \\
\hline Rotor outer diameter & $260 \mathrm{~mm}$ \\
\hline
\end{tabular}

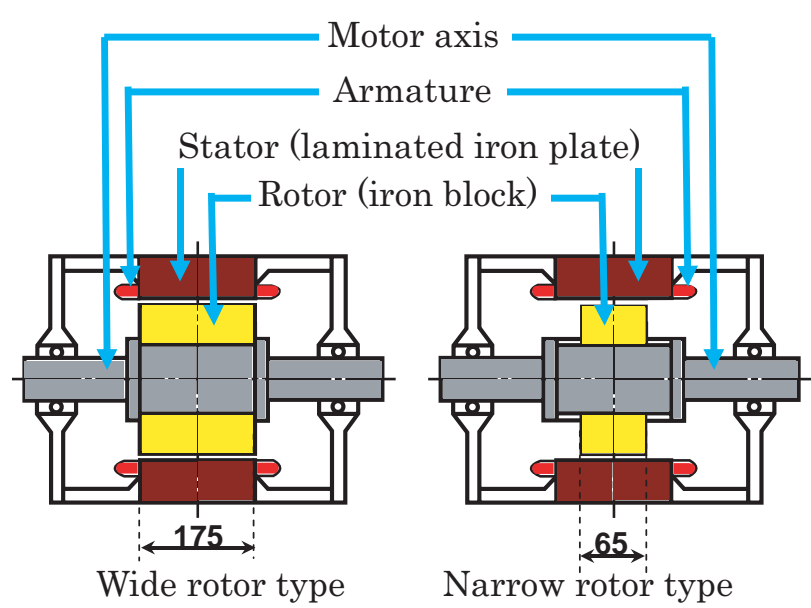

Fig. 6 Rotary-type test machine 
this ratio is shown below. The electric power of the test machine is corrected primary loss such as armature loss.

Rail heating reduction ratio $=$ Electric power $/ \mathrm{Ma}$ chine input

Table 1 shows the parameters of the test machine. Its pole pitch is $212 \mathrm{~mm}$, which is similar to that of the rail brake armature if mounted on the truck. Two types of rotor are prepared. One is a wide rotor with a width of $175 \mathrm{~mm}$ (the same as a regular induction motor rotor), and the other is a narrow rotor with a width of $65 \mathrm{~mm}$ (the same as the head of the rail). Figure 6 shows an axial sectional view of the rotary-type test machine.
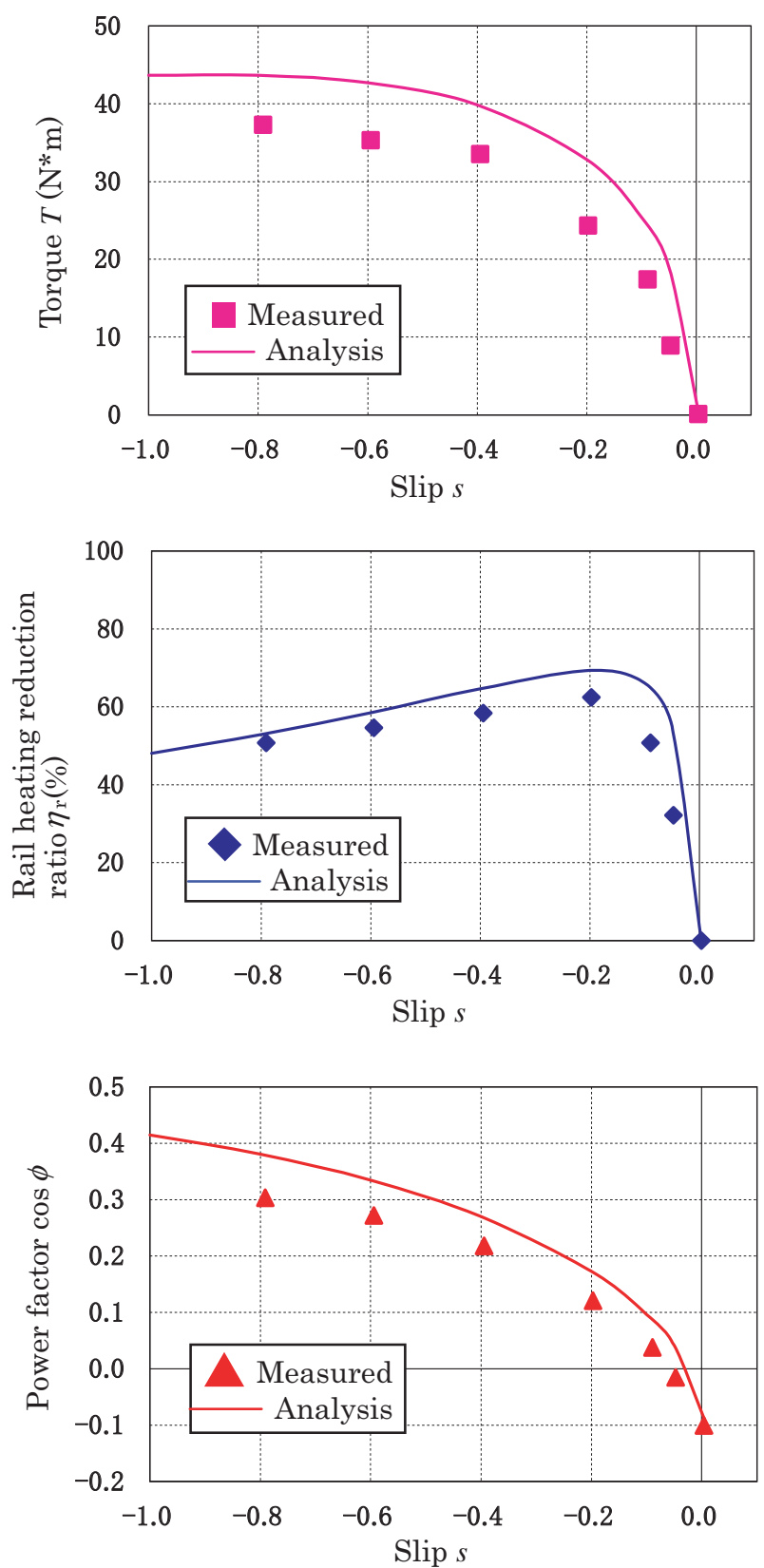

Fig. 7 Slip characteristics (Wide rotor type, $33.4 \mathrm{~Hz}, 48 \mathrm{~A}$ )

\subsection{Braking test}

The slip characteristics of the test machine are measured in braking operation in the same way as measurement for an induction motor in regenerative braking operation. The slip characteristics of the test machine in braking operation under constant current excitation at $33.4 \mathrm{~Hz}$, corresponding to a synchronous speed of $50 \mathrm{~km} /$ h, are shown in Fig. 7 (wide rotor) and Fig. 8 (narrow rotor).

No remarkable difference is seen when the torque is converted into unit length, although the torque changes with the rotor width. There is also no difference in the rail heating reduction ratio; only the power factor is af-
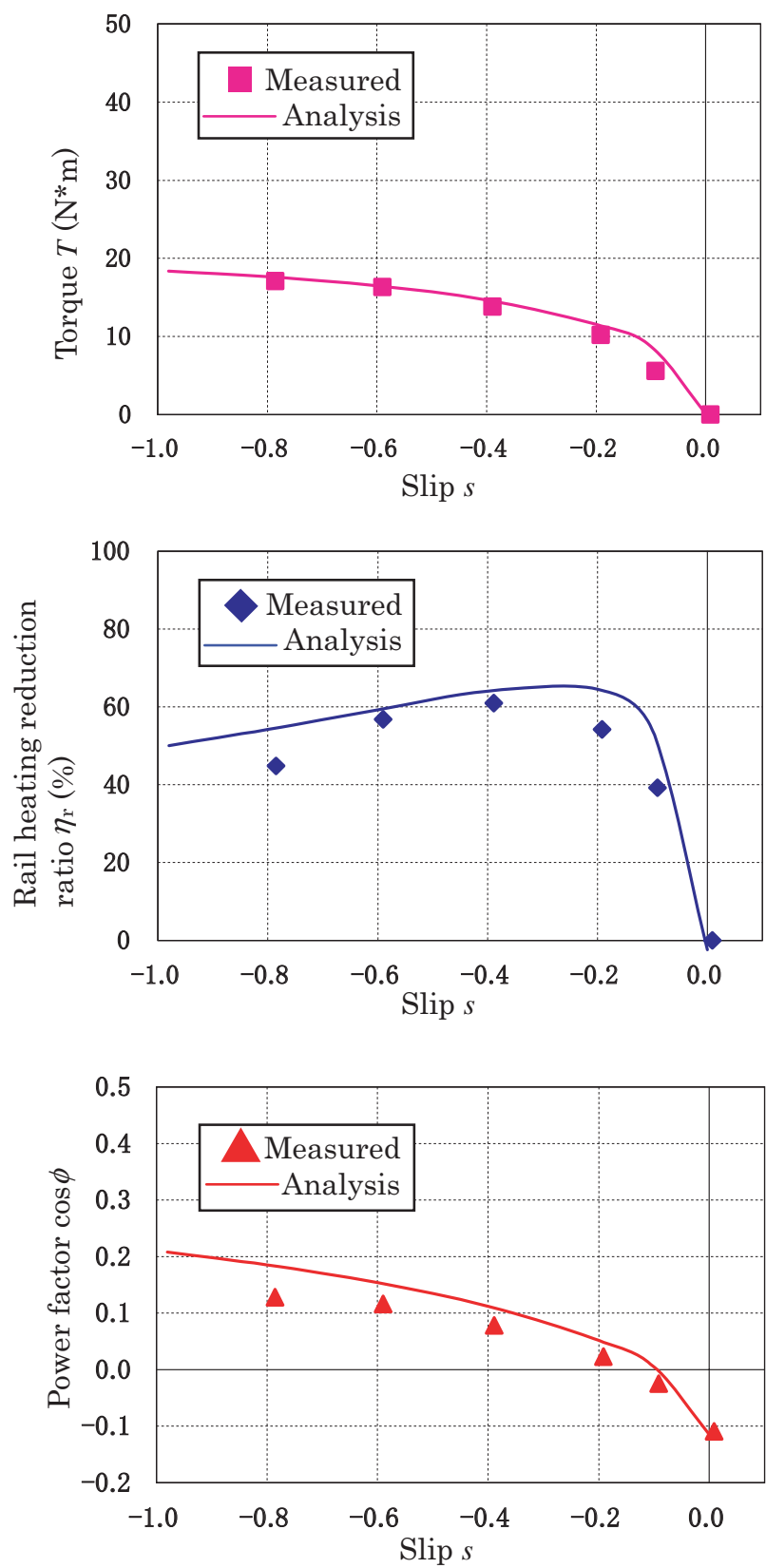

Fig. 8 Slip characteristics (Narrow rotor type, $33.4 \mathrm{~Hz}, 48 \mathrm{~A}$ ) 
fected by the difference in rotor width. In this machine, the armature width is not narrowed compared to the width of the rotor, so the power factor of the narrow rotor is especially low. From these results, the effects of the rail (the secondary conductor) narrowness compared with the primary armature electromagnet pole pitch are not large (other than the power factor). The results of theoretical Fourier series analysis [5] approximately correspond to the experimental results. In Fig. 7 and 8, torque increases with slip, and eventually becomes saturated. On the other hand, the rail heating reduction ratio decreases gradually as slip increases. Accordingly, the rail brake should be controlled at a high slip to obtain the target braking force, as long as the rail heating reduction ratio stays at the design value. A high slip operation is effective in reducing the capacity of the inverter. Moreover, these characteristics are also important in designing the control system for the inverter.

\subsection{Starting characteristics test}

Figure 9 shows the results of the starting characteristics test for dynamic braking without electrical output. It shows a demonstration of equipment reduction priority idea (b) among the two ideas in (a) and (b) described in Chapter 2.

Excitation was initiated with a low DC voltage power source (the inverter power supply). The DC voltage was then increased by the electrical power generated from braking operation. Finally, a stable DC voltage and a stable braking force were achieved by controlling the inverter to balance the generated power and the copper loss of the rail brake armature.

The two points outlined below should be noted in relation to the power supply system of the AC-excitation eddy-current rail brake. The first is that a large-capacity inverter is needed if the rail heating reduction ratio is set high because of the low power factor. The second is that adaptation ability is changed by the processing selection of generated power in the emergency situation of a feeding circuit fault or a main circuit fault. The two ideas (a) and (b) outlined in Chapter 2 are based on these points, and the function of the $\mathrm{AC}$ excitation rail brake that can be added to an existing vehicle brake system is different. Specifically, the equipment reduction priority idea in (b) offers reliability improvement of the brake

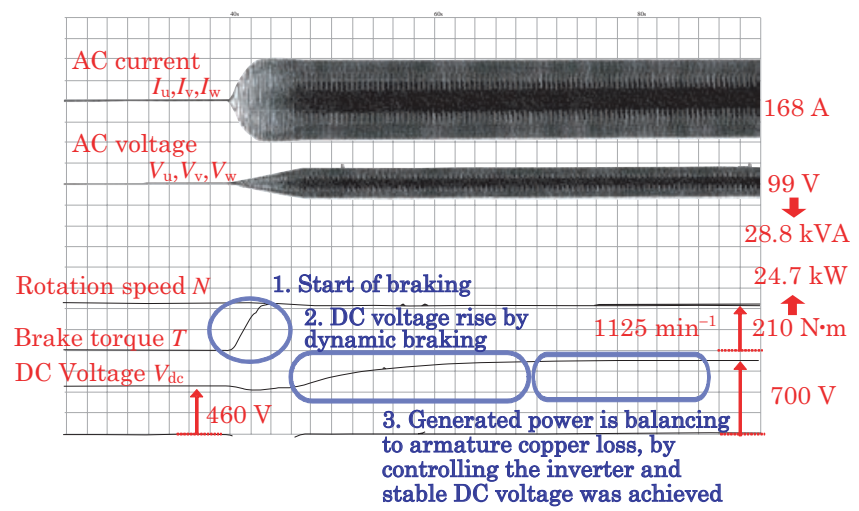

Fig. 9 Starting characteristics test system, and the rail heating reduction ratio priority idea in (a) makes the best use of the functions peculiar to the AC-excitation rail brake, which will offer differing levels of added value depending on the power supply system.

In this examination, the fundamental operation of equipment reduction priority idea (b) that achieves brake system reliability improvement was confirmed; we plan to improve the control system for this idea as part of future development.

\subsection{Influence of the end effect}

In general, no end effect exists in the rotating machine. However, in the linear induction motor, it is assumed that there is a negative effect on various characteristics of the electrical equipment by the end effect. However, these influences may not be significant in the rail brake for the following reasons [6]:

* Although the regenerative ratio (the rail heating reduction ratio) is reduced by the end effect, rail brake operation is assumed to be in the high slip area where the influence of the end effect is comparatively low.

* Because the resistivity of the secondary conductor (iron) is high, the influence of the end effect is not expected to be remarkable.

\section{Preliminary review of several type winding methods}

In the above, the rotary-type test machine is remodeled from an ordinary induction machine, and the armature winding is a general double-layer winding. However, a double-layer winding has a large coil end, and difficulties related to installation on trucks are expected in the actual machine design of the rail brake. To review this, different types of winding were examined through electromagnetic analysis using the Finite Element Method before the design of the actual-scale armature to be created in the future.

This study compared four simplified winding methods: single-layer winding, double-layer winding, doublelayer winding (full pole pitch) and ring winding. The concrete winding method is shown in Fig. 10. When comparing these methods, each winding section was analyzed, and the current density values were assumed to be identical. Figures 11 and 12 show the braking energy (the product of speed and kinetic energy) and the rail heating reduction ratio. Ring winding is a useful technique that improves both the braking force (braking energy) and the rail heating reduction ratio. For installation on a truck, it is difficult to set up two-layer winding (full pole pitch) corresponding to a high magnetomotive force in the limited space on the lower side of the truck, and single-layer winding or ring winding are advantageous in this case. From the results of this review, we selected ring winding as the present examination subject.

\section{Conclusions}

In this study, we examined the basic characteristics 


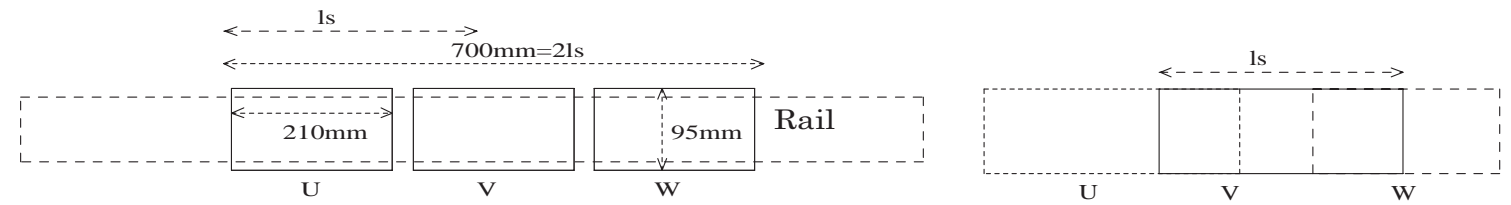

Single-layer winding (each coil current: I) Double-layer winding (full pole pitch; each coil current: I)

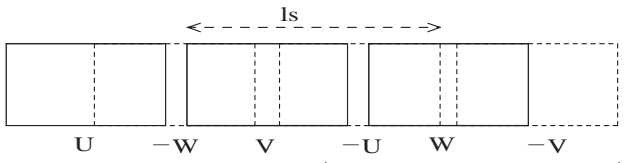

Double-layer winding (each coil current: I/2)

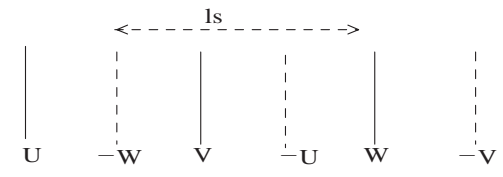

Ring winding (each coil current: I)

Fig. 10 Winding methods

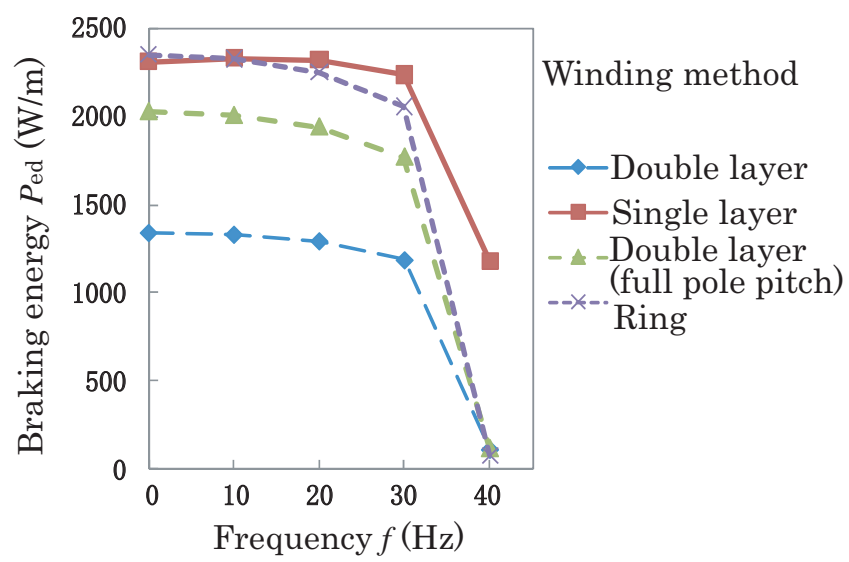

Fig. 11 Braking energy (Braking force)

of the AC-excitation eddy-current rail brake. The results indicate that a rail heating reduction ratio of $30 \%$ or more can be achieved depending on slip. In terms of braking force, the experimental results correspond to those of the analysis. Moreover, we selected the ring winding method for the actual rail brake winding to achieve both a sufficient braking force and a suitable rail heating reduction ratio. A current increase is necessary to evaluate the exact braking force of an actual rail brake because the examination was executed using a light load. Although some uncertainty due to the examination not performed on an actual machine, the power factor related to the power supply capacity is not expected to be high. The reduction in the required power supply as a result of improvements to the power supply facility and optimization of the armature composition will be examined in a future work.

\section{Afterword}

In this paper, we examined the basic characteristic of the AC-excitation eddy-current rail brake using linear motor technology, and the composition of the device was found to be feasible. After considering factors such as the rolling stock gauge, we plan to examine concrete specifications for the armature of the rail brake and the inverter of the system in the future. We are aiming at the achievement of a braking force of approximately $10 \mathrm{kN}$ per truck in these studies.

We would like to thank all concerned in advance for their understanding and help related to rail brake development in the future.

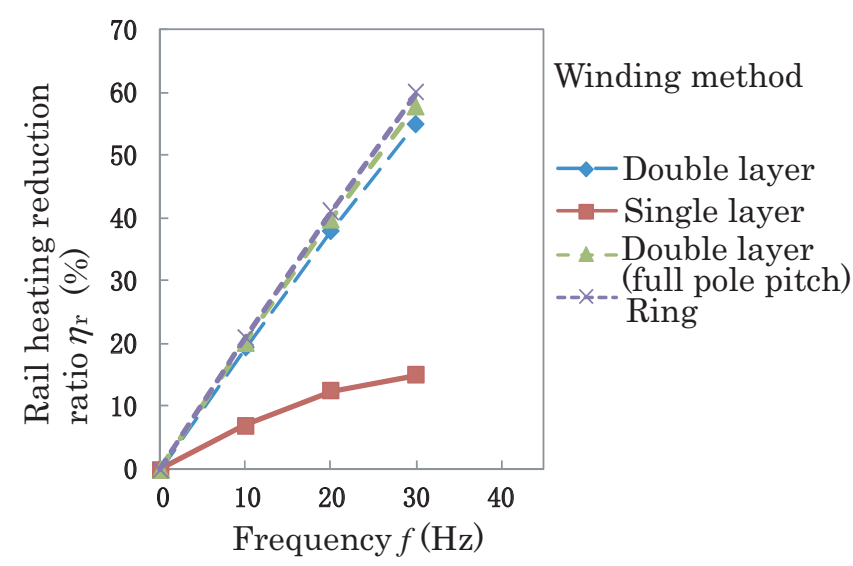

Fig. 12 Rail heating reduction ratio

\section{References}

[1] Nankyo, M., Nakazawa, S., "Application of Real time Estimation for Friction Coefficients of Brake Shoe," RTRI Report, Vol. 19, No. 5, pp. 39-44, 2005.5 (in Japanese).

[2] Ohno, K., Ban, T., Obara, T., Kawaguchi, K., "Ceramics Particle Jetting System to Improve Adhesion between Wheel and Rail during High Speed Running," RTRI Report, Vol. 9, No. 1, pp. 31-36, 1995.1 (in Japanese).

[3] Obara, T., Maruoka, A., Yoshikawa, T., Kageyama, T., Takiguchi, T., "An Emergency Brake System for Conventional Lines," Proceedings of the International Symposium on Railroad Cybernetics, pp. 252-256, 1991 (in Japanese).

[4] Matsumura, S., Uchida, S., Kumagai, N., Obara, T., "Elemental Characteristics of Hybrid Rail Brake for Shinkansen," RTRI Report, Vol. 12, No. 1, pp. 11-16, 1998.1 (in Japanese).

[5] Sakamoto, Y., Murai, T., Sasakawa, T., "The basic Study of A.C. excited eddy-current rail brake.," Papers of the Technical Meeting on Linear Drives, IEE Japan, LD-04-34, 2004.6 (in Japanese).

[6] Sakamoto, Y., Kashiwagi, T., Sasakawa, T., Tanaka, M., "Basic characteristics of LIM type rail brake," Papers of the Joint Technical Meeting on Linear Drives and Semiconductor Power Converters, IEE Japan, SPC07-139, LD-07-66, 2007.12 (in Japanese). 